\title{
Chromosomal composition of aneuploid clones with different DNA contents in head and neck squamous cell carcinomas as determined by combined flow cytometry and fluorescence in situ hybridization
}

\author{
Joerg Hemmer* and Carmen Hauser \\ Division of Tumor Biology, University of Ulm, Ulm, \\ Germany
}

\section{Received 7 April 2000}

Accepted 21 September 2000

Studies with DNA flow cytometry (FCM) have shown that DNA contents of aneuploid tumour clones vary in a wide range. The aim of this study was to analyse whether homologous chromosomal changes exist despite the individual differences that may be of general relevance for the development of gross aneuploidy in squamous cell carcinomas of the head and neck. Fluorescence in situ hybridization (FISH) with 13 centromere-specific DNA probes was applied to 3 diploid and 11 aneuploid tumours with DNA indices ranging between 0.8 and 2.2. Disomic and monosomic cell populations were prevalent findings in DNA-diploid tumours. Polysomies were common in aneuploid tumours. Different degrees of aneusomy for identical chromosomes were recurrent features in aneuploid tumours. FISH signal heterogeneity was identified for all chromosomes. The mean number of aneusomic cell populations identified for DNA-aneuploid tumours ranged between 1.6 for chromosome 17 and 3.1 for chromosome 3. Inconsistencies between FISH and FCM data may indicate that centromere-specific DNA probes identify gains and losses of marker DNA due to complex karyotypic rearrangements rather than absolute changes in chromosome numbers. Overall, there was no evidence of the critical involvement of particular chromosomes in the development of different DNA contents.

\footnotetext{
*Corresponding author: Professor Dr Joerg Hemmer, Ph.D., Division of Tumor Biology, University of Ulm, P.O. Box 1220, D-89070 Ulm, Germany. Tel: +49 731502 3754; Fax: +49 731502 3758; E-mail: joerg.hemmer@medizin.uni-ulm.de.
}

Keywords: Head and neck cancer, squamous cell carcinoma, fluorescence in situ hybridization, DNA flow cytometry, aneuploidy

\section{Introduction}

DNA flow cytometric studies on squamous cell carcinomas of the head and neck have shown that early tumours mostly compose of diploid cells, while the proportion of carcinomas accommodating cell populations with atypical DNA content increases with degree of tumour progression to nearly one hundred percent in the most advanced stages [1]. This suggests a preferred sequence of genetic evolutionary changes which regularly results in the evolution of aneuploid cell strains from diploid progenitor cells during undisturbed tumour progression [2]. Aneuploidy commonly associates with losses of heterozygosity in a substantial proportion of alleles [3]. The reorganisation of the tumour cell genome during aneuploidy formation may therefore facilitate malignancy progression by increasing the rate at which tumour suppressor genes are lost. Aneuploidy has actually turned out to be an independent prognostic factor in head and neck squamous cell carcinoma [4-6]. The fatal outcome of patients with aneuploid tumours is substantially determined by a several-fold increase in risk of developing metastasis to the neck and local recurrence after aneuploid clones have emerged [6-11].

Amazingly, neither the metastatic behaviour of tumours nor the outcome of patients turned out to correlate with the wide variation of DNA contents in aneuploid carcinomas [2,7]. This is despite an increasing 
Table 1

Clinical, histopathologic and DNA flow cytometric characteristics of the patients

\begin{tabular}{rlccccc}
\hline Case & Localisation & $\mathrm{T}$ & $\mathrm{N}$ & $\mathrm{M}$ & $\begin{array}{c}\text { Histologic } \\
\text { differentiation }\end{array}$ & $\begin{array}{c}\text { DNA } \\
\text { index }\end{array}$ \\
\hline 1 & Tongue & 2 & 0 & 0 & High & 1.0 \\
2 & Lower lip & 1 & 0 & 0 & High & 1.0 \\
3 & Tongue & 2 & $2 \mathrm{~b}$ & 0 & Poor & 1.0 \\
4 & Larynx & 2 & $2 \mathrm{~b}$ & 0 & Poor & 0.8 \\
5 & Floor of mouth & 2 & 2 & 0 & Moderate & 0.9 \\
6 & Cheek mucosa & 2 & 0 & 0 & Moderate & 1.1 \\
7 & Tongue & 2 & 1 & 0 & Moderate & 1.4 \\
8 & Palate & 2 & 2 & 0 & Moderate & 1.5 \\
9 & Hypopharynx & 2 & 0 & 0 & Poor & 1.5 \\
10 & Upper jaw & 4 & 0 & 0 & Moderate & 1.7 \\
11 & Tongue & 2 & $2 \mathrm{~b}$ & 0 & Moderate & 1.8 \\
12 & Floor of mouth & 2 & $2 \mathrm{~b}$ & 0 & Poor & 1.9 \\
13 & Larynx & 3 & 0 & 0 & Moderate & 2.0 \\
14 & Tongue & 1 & 1 & 0 & Moderate & $1.4 / 2.2$ \\
\hline
\end{tabular}

divergence of aneuploid DNA content from the normal diploid value implies a corresponding gain in underlying karyotypic complexity. The aim of this study was to analyse whether tumour clones with different in DNA contents have chromosomal changes in common that may account for their inherent malignant behaviour.

\section{Material and methods}

\subsection{Selection of patients}

Exclusively primary and previously untreated squamous cell carcinomas of the head and neck were considered. According to DNA flow cytometric examinations of preoperative biopsies, 3 diploid as well as 11 aneuploid tumours with relative DNA contents ranging between 0.8 and 2.2 were selected for this study (Table 1).

\subsection{DNA flow cytometry}

FCM was carried out as previously described [5,9]. In short, fresh tissue pieces were homogenized in $0.9 \%$ $\mathrm{NaCl}$ by thoroughly mincing with surgical scalpels. The nuclei were extracted by incubation in $0.5 \%(\mathrm{w} / \mathrm{v})$ acid pepsin solution $(\mathrm{pH} 1.5)$ with careful stirring for 5 minutes, strained through a $50 \mu$ m nylon mesh, and fixed with $70 \%$ ethanol. The nuclei were stained with $5 \mu \mathrm{M}$ DAPI solution (Serva, Heidelberg, Germany) containing $0.2 \mathrm{M}$ trisodium citrate dihydrate $(\mathrm{pH} \mathrm{8.0)}$.
FCM was carried out using a PAS II or a PAS III flow cytometer equipped with a high-pressure $100 \mathrm{~W}$ mercury lamp (Partec, Münster, Germany). The diploid cell population was used as a reference standard for the identification of aneuploid clones. Human lymphocytes were added in a control measurement if the diploid cell population could not unambiguously be identified.

\subsection{Fluorescence in situ hybridization}

Nuclei were extracted by mincing fresh tissue samples with surgical scalpels in $2.5 \%(\mathrm{w} / \mathrm{v})$ citric acid. Tissue fragments were removed using a $50 \mu \mathrm{m}$ nylon mesh. The suspension was then passed through a Dounce homogeniser with a piston-vessel distance of $200 \mu \mathrm{m}$. Nuclei were sedimented by sucrose centrifugation, fixed in cold $3: 1$ methanol-acetic acid and stored at $-20^{\circ} \mathrm{C}$. FISH with digoxigenin-labelled, centromere-specific DNA probes (Oncor-Appligene, Heidelberg, Germany) was performed on slides using standard protocols. In short, fixed nuclei were spun onto silane-coated slides and air dried. After incubation in $2 \times \mathrm{SSC}$ buffer (Sigma, Deisenhofen, Germany) for 30 minutes at $37^{\circ} \mathrm{C}$, the slides were dehydrated in ascending ethanol and air dried. The slides were than incubated in $70 \%$ formamide $/ 2 \times \mathrm{SSC}$ for 2 minutes at $70^{\circ} \mathrm{C}$ and carried through an ascending $-20^{\circ} \mathrm{C}$ alcohol series. A solution was prepared containing $1.5 \mu \mathrm{l}$ of DNA probe and $30 \mu \mathrm{l}$ of $65 \%$ formamide $/ 2 \times \mathrm{SSC} / 10 \%(\mathrm{w} / \mathrm{v})$ dextran sulphate. After 
Table 2

Results of FISH with chromosome-specific DNA probes for an aneuploid carcinoma with a DNA index of 1.9 (case 12)

\begin{tabular}{|c|c|c|c|c|c|c|c|c|c|c|c|c|}
\hline \multirow[t]{2}{*}{ Signals per cell } & \multicolumn{12}{|c|}{ Chromosome } \\
\hline & 1 & 2 & 3 & 6 & 7 & 8 & 10 & 11 & 12 & 15 & 16 & 17 \\
\hline 0 & - & - & - & - & - & - & - & - & - & - & - & - \\
\hline 1 & - & 13 & 12 & 12 & - & 11 & 26 & 10 & - & 36 & 19 & - \\
\hline 2 & 43 & 64 & 37 & 73 & 71 & 56 & 74 & 55 & 82 & 58 & 60 & 73 \\
\hline 3 & 25 & 17 & 18 & 3 & 6 & 20 & - & - & 18 & 6 & 5 & 6 \\
\hline 4 & 25 & 6 & 20 & 12 & 23 & 10 & - & 35 & - & - & 15 & 20 \\
\hline 5 & 3 & - & - & - & - & 4 & - & - & - & - & - & - \\
\hline \multirow[t]{3}{*}{6} & 4 & - & 14 & - & - & - & - & - & - & - & - & - \\
\hline & 4 & 3 & 4 & 3 & 2 & 4 & 1 & 2 & 1 & 2 & 3 & 2 \\
\hline & \multicolumn{12}{|c|}{ Number of aneusomic subpopulations } \\
\hline
\end{tabular}

5 minutes incubation at $70^{\circ} \mathrm{C}$, the hybridisation solution was placed onto sample slides, coverslipped, and hybridised overnight at $37^{\circ} \mathrm{C}$. Hybridisation was visualised using FITC-conjugated anti-digoxigenin Fab fragments (Roche Diagnostics, Mannheim, Germany). The slides were counterstained with DAPI/Antifade (Oncor-Appligene).

\subsection{Evaluation of FISH results}

At least 200 nuclei per slide were counted. Control hybridisations were performed on tonsillectomy specimens to define cut-off values for assuming true aneusomic subpopulations in the respective tumour samples. Following a proposal of Soder et al. [12], the diagnostic thresholds were defined as the mean plus three standard deviations as assessed for the control hybridisations. Nullosomy in a tumour sample was thus assumed if the relative number of cells without any FISH signal for a respective chromosome exceeded $7 \%$. The cut-off values were $10 \%$ for monosomy, $5 \%$ for trisomy, and $3 \%$ for $>3$ polysomies, respectively.

\section{Results}

Fourteen primary squamous cell carcinomas of the head and neck were selected on routine FCM measurements with the intention to collect a series of tumours that cover a wide range of DNA content aberrations. The coefficients of variation of the FCM measurements ranged between 1.40 and $2.07 \%$ with a mean value of $1.68 \%$ (SD $=0.21)$. Three tumours consisted exclusively of flow cytometrically diploid cells. Ten carcinomas expressed each a single cell line with atypical DNA content. One tumour contained two different ane- uploid clones. The DNA indices ranged between 0.8 and 2.2.

A carcinoma containing an aneuploid clone with a DNA index of 1.9 (case 12), has been used to illustrate the outcome of FISH analysis with chromosomespecific DNA probes (Table 2). This tumour showed aneusomies for each of chromosomes analysed. Two chromosomes exhibited a single aneusomic cell population, precisely a monosomy 10 and a trisomy 12 . All other chromosomal analyses exposed two or more simultaneous cell populations with different degree of aneusomy. The proportion of cells with diploid DNA content by FCM $(65 \%)$ clearly exceeded the relative number of cells carrying a disomy for chromosomes 1 and 3, thus indicating the development of karyotypic aberrations also for flow cytometrically diploid tumour cells. In like manner, the proportions of DNAdiploid cells exceeded the respective minimum fraction of cells with disomy for particular chromosomes by 6 to $52 \%$ (median $=16 \%$ ) also for all other aneuploid tumours.

Table 3 summarises the number of cell populations with different degree of aneusomy for each of chromosomes analysed in the current cases. Although disomic cell populations were obtained for altogether 147 chromosomal examinations done, there were only 15 sample cell populations (10.2\%) that consisted entirely of disomic cells for a particular chromosome. Lack of aneusomy was identified in 11 of 28 FISH tests performed in diploid tumours $(39.3 \%)$. This was in contrast to 4 entirely disomic cell samples found among 119 preparations $(3.4 \%)$ done in the aneuploid group $(P<0.01$; chi-square probability test $)$. Thirty-seven of chromosomal preparations $(25.2 \%)$ revealed a single aneusomic cell population in addition to disomic cells. The majority of 95 experiments $(64.6 \%)$ exposed between two and five simultaneous cell fractions with 
Table 3

Correlation between DNA content and number of aneusomic cell populations ${ }^{\mathrm{a}}$

\begin{tabular}{|c|c|c|c|c|c|c|c|c|c|c|c|c|c|c|c|}
\hline Case number & 1 & 2 & 3 & 4 & 5 & 6 & 7 & 8 & 9 & 10 & 11 & 12 & 13 & 14 & $\mathrm{HI}^{\mathrm{b}}$ \\
\hline DNA index & 1.0 & 1.0 & 1.0 & 0.8 & 0.9 & 1.1 & 1.4 & 1.5 & 1.5 & 1.7 & 1.8 & 1.9 & 2.0 & $1.4 / 2.2$ & \\
\hline \multicolumn{16}{|l|}{$\begin{array}{l}\text { Chromosome } \\
\text { number }\end{array}$} \\
\hline 1 & 0 & - & - & - & 0 & - & 1 & 2 & 3 & - & 2 & 4 & - & 4 & 2.29 \\
\hline 2 & 0 & - & 2 & 1 & 1 & 1 & 2 & 2 & 3 & 2 & 2 & 3 & 4 & 4 & 2.27 \\
\hline 3 & 0 & 2 & - & - & 2 & - & 2 & 2 & 4 & 4 & 3 & 4 & 4 & 3 & 3.11 \\
\hline 6 & 0 & 2 & 1 & 1 & 1 & 1 & 2 & 2 & 4 & 3 & 2 & 3 & 3 & 3 & 2.27 \\
\hline 7 & 0 & 0 & 1 & 2 & 1 & 0 & 2 & 2 & 2 & 4 & 3 & 2 & 3 & 3 & 2.18 \\
\hline 8 & 1 & 0 & 2 & 2 & 2 & 2 & 2 & 2 & 3 & 3 & 4 & 4 & 5 & 5 & 3.09 \\
\hline 9 & - & 0 & 1 & 1 & - & - & - & - & 3 & 3 & 4 & - & - & 3 & 3.00 \\
\hline 10 & 0 & 1 & 1 & 1 & 2 & 1 & 1 & 1 & 3 & 3 & 3 & 1 & 3 & 5 & 2.18 \\
\hline 11 & - & 1 & 1 & 2 & - & 1 & - & - & 2 & 2 & 2 & 2 & 2 & 4 & 2.13 \\
\hline 12 & 0 & - & 2 & 2 & 2 & 2 & 1 & 1 & 2 & 2 & 1 & 1 & 3 & 5 & 2.00 \\
\hline 15 & - & - & 1 & 1 & - & - & - & - & 3 & 3 & 2 & 2 & 2 & 1 & 2.00 \\
\hline 16 & - & 1 & - & 1 & - & - & - & - & 2 & - & 3 & 3 & 3 & 4 & 2.67 \\
\hline 17 & 0 & 1 & 1 & 2 & 0 & 1 & 2 & 2 & 1 & 1 & 3 & 2 & 2 & 0 & 1.60 \\
\hline $\begin{array}{l}\text { Heterogeneity } \\
\text { index }\end{array}$ & 0.11 & 0.89 & 1.30 & 1.45 & 1.22 & 1.13 & 1.67 & 1.78 & 2.69 & 2.73 & 2.62 & 2.58 & 3.09 & 3.38 & \\
\hline
\end{tabular}

a Disomic cells were only considered if the respective sample cell populations consisted entirely of disomic cells $(=0) .1=$ a single aneusomic cell population in addition to disomic cells. 2, 3, 4, 5= two, three, four, five cell populations with different aneusomic FISH signals for respective chromosomes. $\mathrm{HI}=$ mean number of aneusomic clones (heterogeneity index).

${ }^{\mathrm{b}}$ Aneuploid cases only. Hyphens indicate missing values.

different numbers of FISH signals for identical chromosomes.

The mean number of aneusomic cell populations (heterogeneity index) ranged between 0.11 for a diploid carcinoma to 3.38 for the flow cytometrically biclonal tumour (Table 3). Linear regression analysis confirmed a strong correlation between the heterogeneity index and the degree of DNA content deviation from the normal diploid value $(r=0.9164$; $P<0.01$; two-tailed $t$-test). Increasing DNA content abnormality was also accompanied by increasing number and degree of polysomy (Table 4). Entirely disomic and monosomic cell populations were the most prevalent findings in DNA-diploid tumours. Also in DNAaneuploid carcinomas, polysomic cell populations frequently concurred with cells carrying a monosomy of homologous chromosomes. There were also notable chromosome-specific differences in FISH signal number heterogeneity (Table 3). If only the aneuploid cases were considered, a correlation matrix (not shown) exposed statistical significance $(P<0.05$; Mann and Whitney $U$-test) for distribution differences in casespecific numbers of aneusomic cell populations between chromosome 17 and chromosomes 3, 9 and 16 as well as between chromosomes 12 and 3 . However, there was no association between the degree of DNA content aberration and the involvement of particular chromosomes.

\section{Discussion}

Substantial evidence has been accumulated demonstrating that the acquisition of gross aneuploidy is a regular event in the genetic evolution of human solid tumours $[3,13,14]$. However, the mechanisms underlying aneuploidy formation are largely unknown, particularly if distinct cytogenetic pathways exist for the development of different karyotypic patterns. Differences in DNA content aberrations reflect the genetic variability of most malignant tumours. Convincingly, the degree of DNA content deviation from the normal diploid value must correlate with an analogous loss or gain of chromosomal material. Only a limited number of chromosomal changes, and probably those critical for the expression of invasive and metastatic growth patterns in head and neck cancer [2,7], are consequently expected to underlie the development of aneuploid clones with minor DNA content aberrations. 
Table 4

Correlation between DNA content and degree of aneusomy ${ }^{\mathrm{a}}$

\begin{tabular}{|c|c|c|c|c|c|c|c|c|c|c|c|c|c|c|}
\hline Case number & 1 & 2 & 3 & 4 & 5 & 6 & 7 & 8 & 9 & 10 & 11 & 12 & 13 & 14 \\
\hline DNA index & 1.0 & 1.0 & 1.0 & 0.8 & 0.9 & 1.1 & 1.4 & 1.5 & 1.5 & 1.7 & 1.8 & 1.9 & 2.0 & $1.4 / 2.2$ \\
\hline Number of chromosomes analysed & 9 & 9 & 10 & 11 & 9 & 8 & 9 & 9 & 13 & 11 & 13 & 12 & 11 & 13 \\
\hline \multicolumn{15}{|l|}{ Number of clones with } \\
\hline Nullosomy & - & - & - & 2 & - & - & - & - & - & 1 & 1 & - & 1 & - \\
\hline Monosomy & 1 & 5 & 10 & 8 & 6 & 5 & 3 & 3 & 10 & 5 & 8 & 8 & 7 & 6 \\
\hline Disomy $^{b}$ & 8 & 3 & - & - & 2 & 1 & - & - & - & - & - & - & - & 1 \\
\hline Trisomy & - & 2 & 2 & 3 & 5 & 2 & 6 & 7 & 12 & 9 & 10 & 10 & 10 & 11 \\
\hline Tetrasomy & - & 1 & 1 & 3 & - & 2 & 6 & 6 & 10 & 10 & 12 & 9 & 9 & 11 \\
\hline Pentasomy & - & - & - & - & - & - & - & - & 3 & 2 & 3 & 1 & 2 & 3 \\
\hline Hexasomy & - & - & - & - & - & - & - & - & - & 3 & - & 2 & 3 & 9 \\
\hline Heptasomy & - & - & - & - & - & - & - & - & - & - & - & - & - & 1 \\
\hline Octosomy & - & - & - & - & - & - & - & - & - & - & - & - & 2 & 2 \\
\hline
\end{tabular}

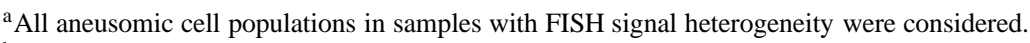

${ }^{\mathrm{b}}$ Only chromosomal examination revealing entirely disomic findings are listed.

As did other studies on head and neck squamous cell carcinomas [15-17], we observed a consistent increase of polysomic findings with increasing degree of DNA content abnormality, but we did not find any evidence for a preferential involvement of particular chromosomes in the development of different DNA contents. In spite of that, frequent aneusomies in DNA-diploid tumours as well as the broad FISH signal number heterogeneity in tumours seemingly monoclonal by FCM were conflicting observations. Heterogeneous findings with chromosome enumeration probes have frequently been reported [12,16-18]. Most of these studies tried to circumvent interpretation by focussing mainly on dominant aneusomic cell fractions. For others, implausibility between FISH and FCM data gave reason to dispute which of the techniques may be the more advantageous one [19]. However, cellular karyotypes and DNA contents must necessarily be compatible. There is consequentially no biological foundation for assuming inconsistencies between FISH and FCM other than those relying on data acquisition or interpretation.

One of the reasons evidently contributing to increase the heterogeneity of FISH signal numbers is the coexistence of DNA-diploid and aneuploid malignant cells in the same tumour. We have recently demonstrated with biparameter FCM of DNA and cytokeratin content that DNA-diploid tumour cells persist in head and neck squamous cell carcinomas also after aneuploid clones have developed [20]. This is consistent with the difference between the proportions of DNA-diploid and disomic cells in the present study indicating that flow cytometrically diploid tumour cells with minor cytogenetic aberrations coexist with DNA-aneuploid clones in the same tumour. Monosomies were actually the most prevalent chromosomal aberrations assessed for DNA-diploid tumours. Despite the increase in number and degree of polysomy with increasing DNA content aberration, also aneuploid carcinomas frequently exposed concurrent monosomies. This may indicate a preferential loss of chromosomal markers also for the DNA-diploid cellular constituents of aneuploid tumours.

However, monosomies in DNA-diploid tumours expose a flagrant disagreement between FCM and FISH data. Also by metaphase analysis, seemingly diploid head and neck carcinomas have occasionally been demonstrated to exhibit karyotypic aberrations [21]. It would therefore be reasonable to speculate that diploidy by FCM simply reflects methodical limitations to resolve clones with minor DNA content aberrations from non-malignant cellular components. However, high-resolution DNA flow cytometry allows discrimination between $\mathrm{x}$ and $\mathrm{y}$-bearing sperm cells, thus representing a 3\% difference in DNA content [22]. Also the coefficients of variation that ranged between $1.4 \%$ and $2.1 \%$ for the current tumours would allow to detect clonal DNA content aberrations resulting in an approximately $2-4 \%$ deviation from the normal diploid value, and by that even gains and losses of a single major chromosome [5,23]. Using this highresolution FCM technique, we recently reported survival rates of more than $80 \%$ for patients with flow cytometrically diploid oral carcinomas in contrast to rates of less than $50 \%$ for the aneuploid group. This difference was independent of tumour size or differentiation [2,5], of whether the tumours were primaries 
or recurrences [9] and of whether the patients were treated by surgery alone or with induction chemotherapy [24,25]. This ploidy-specific difference in outcome applied in like manner to tumours accommodating aneuploid clones with minor DNA content aberrations [2,7]. This signifies that diploid and near-diploid carcinomas are separate prognostic entities and that the detection of minor DNA content aberrations by high-resolution FCM is not an incidental finding [5, 7]. Aneuploid cells with minor DNA content aberration and flow cytometrically diploid tumour cells must consequentially differ in a crucial imbalance of chromosomal material that may account for the dramatic difference in biological malignancy despite the small alteration in DNA content.

However, such as aneusomic findings in DNAdiploid tumours, also the extensive heterogeneity of FISH counts in aneuploid tumours seems to be out of keeping with the monoclonal appearance by FCM. It appears that the basic assumption that centromerespecific DNA probes permit a reliable determination of chromosome numbers must be called in question so far as solid malignancies are concerned. Also seemingly nullosomal cell populations provide evidence that numerical changes of FISH markers, particular of those hybridising to non-coding centromeric repeat units, not necessarily indicate gains or losses of whole chromosomes. In fact, the often complex karyotypes of solid malignancies are mostly characterised by an extensive exchange of DNA between original chromosomes and the frequent assembly of entirely new chromosomal entities.

This indicates that the concept of chromosomes as applicable to non-malignant human cells cannot readily be translated into karyotypic patterns of neoplastic cells. Atypical numbers of FISH markers may therefore reflect the overall complexity of tumour cell karyotypes rather than changes of chromosome numbers alone. It thus appears that centromere-specific DNA probes alone provide an only approximate estimation of the range and specificity of chromosomal alterations in solid tumours. Simultaneous application of locusspecific FISH markers would certainly contribute to improve the identification of chromosomal changes [26]. This also applies to comparative genomic hybridisation which actually illustrated comprehensive deletions and amplifications of chromosomal material in head and neck squamous cell carcinoma [27].

Nevertheless, atypical FISH signal numbers substantiate the clonal manifestation of cytogenetic changes. Heterogeneity despite the identification of sin- gle aneuploid clones by FCM may therefore suggest a monoclonal origin. This is in line with the idea of an unequal mitosis of flow cytometrically diploid progenitor cells as the genetic mechanisms underlying the development of clones with gross karyotype aberrations $[2,13,28]$. Heterogeneity of FISH signal numbers may thus indicate secondary changes of the original aneuploid karyotype. Despite this general competence for clonal diversification, FCM studies have shown that head and neck carcinomas mostly contain a single aneuploid clone, and no changes of FCM patterns in favour of multiconality has been observed during tumour progression [2]. Although individual tumours develop clones with widely differing DNA contents [2, 7], DNA-aneuploid cell populations are characterised by a pronounced stability during metastasis and recurrence development $[7,9,20,24,25]$. These observations strongly suggest mechanisms that determine the acquisition and maintenance of particular karyotypic patterns. Analogously, the bimodal DNA index frequency distribution pattern, which is characterised by a distinct gap between aneuploid clones with DNA contents not exceeding a DNA index of 1.3 and those with higher DNA indices [2,7], may point to an elimination of particular karyotypes by either mitotic mechanisms or post-mitotic selection.

The question thus remains why head and neck carcinomas develop largely different aneuploid clones with similar malignant behaviour. The current study did not provide any evidence of a diagnostic pattern of chromosomal aberrations. However, it may be of interest that particular chromosomes differ considerably in the degree of heterogeneity. Although any attempt to interpret these findings would at present be speculative, this observation may give reason for future investigations on the nature and function of aneuploidy in head and neck cancer.

\section{Acknowledgement}

This study has been supported by a grant of Rudolf and Clothilde Eberhardt-Stiftung.

\section{References}

[1] J. Hemmer and J. Kreidler, Flow cytometric DNA analysis of squamous cell carcinomas of the oral cavity. Comparison with clinical staging and histologic grade, Cancer 66 (1990), 317320 . 
[2] J. Hemmer and E. Schön, Cytogenetic progression in oral carcinoma: a DNA flow cytometric study on 317 cases, Int. J. Oncol. 3 (1993), 635-640.

[3] C. Lengauer, K.W. Kinzler and B. Vogelstein, Genetic instabilities in human cancers, Nature 396 (1998), 643-649.

[4] R.B. Chen, K. Suzuki, T. Nomura and T. Nakajima, Flow cytometric analysis of squamous cell carcinomas of the oral cavity in relation to lymph node metastasis, J. Oral Maxillofac. Surg. 51 (1993), 397-401.

[5] J. Hemmer, E. Nagel and K. Kraft, DNA aneuploidy by flow cytometry is an independent prognostic factor in squamous cell carcinoma of the oral cavity, Anticancer Res. 19 (1999), 14191422.

[6] J. Hemmer, K. Kraft and J. Kreidler, The significance of DNA flow cytometry in predicting survival and delayed clinical manifestation of occult lymph node metastasis to the untreated neck in patients with oral squamous cell carcinoma, J. CranioMaxfac. Surg. 26 (1998), 405-410.

[7] J. Hemmer, J. Kreidler, W.F.P. Van Heerden, E. Raubenheimer and E. Schön, Flow cytometric cellular DNA content and lymph node metastasis in squamous cell carcinoma of the oral cavity, Int. J. Oncol. 6 (1995), 1237-1242.

[8] J. Hemmer, W.F.P. Van Heerden, E.J. Raubenheimer, J. Kreidler and E. Schön, Flow cytometric DNA ploidy and recurrence development in squamous cell carcinoma of the oral cavity, Int. J. Oncol. 8 (1996), 113-116.

[9] J. Hemmer, T. Thein and W.F.P. Van Heerden, The value of DNA flow cytometry in predicting the development of lymph node metastasis and survival in patients with locally recurrent oral squamous cell carcinoma, Cancer 79 (1997), 2309-2313.

[10] W.W. King, P.K. Lam and A.K. Li, DNA ploidy as a predictor of cervical metastasis in advanced squamous carcinoma of the tongue, Acta Otolaryngol. 115 (1995), 455-458.

[11] T. Saito, J. Sato, A. Satoh, K. Notani, H. Fukuda, S. Mizunza, M. Shindoh and A. Amemiya, Flow cytometric analysis of nuclear DNA content in tongue squamous cell carcinoma: relation to cervical lymph node metastasis, Int. J. Oral Maxillofac. Surg. 23 (1994), 28-31.

[12] A.I. Soder, A.H. Hopman, F.C. Ramaekers, C. Conradt and F.X. Bosch, Distinct nonrandom patterns of chromosomal aberrations in the progression of squamous cell carcinomas of the head and neck, Cancer Res. 55 (1995), 5030-5037.

[13] S.E. Shackney and T.V. Shankey, Common pattern of genetic evolution in human solid tumors, Cytometry 29 (1997), 1-27.

[14] S. Sen, Aneuploidy and cancer, Curr. Opin. Oncol. 12 (2000), 82-88.

[15] J. Hemmer and W. Prinz, Comparison of DNA flow cytometry and fluorescence in situ hybridization with a set of 10 chromosome-specific DNA probes in four head and neck carcinomas, Cancer Genet. Cytogenet. 97 (1997), 35-38.

[16] A.K. El-Naggar, M. Dinh, S. Tucker, M.A. Luna, H. Goepfert, P. Hsu and J.G. Batsakis, Genotypic analysis of primary head and neck squamous cell carcinoma by combined fluorescence in situ hybridization and DNA flow cytometry, Am. J. Clin. Pathol. 105 (1996), 102-108.

[17] J.A. Veltman, A.H.N. Hopman, S.A. van der Vlies, F.J. Bot, F.C.S. Ramakers and J.J. Manni, Double-target fluorescence in situ hybridization distinguishes multiple genetically aberrant clones in head and neck squamous cell carcinoma, Cytometry 34 (1998), 113-120

[18] N. Voravud, D.M. Shin, J.Y. Ro, J.S. Lee, W.K. Hong and W.N. Hittelman, Increased polysomies of chromosomes 7 and 17 during head and neck multistage tumorigenesis, Cancer Res. 53 (1993), 2874-2883.

[19] F. Ramakers, A. Hopman and P. Vooijs, Advances in the detection of ploidy differences in cancer by in situ hybridization, Analyt. Cell. Pathol. 4 (1992), 337-344.

[20] J. Polackova and J. Hemmer, Progression of diploid tumor cells in aneuploid head and neck squamous cell carcinomas, Int. J. Oncol. 15 (1999), 315-320.

[21] J. Akervall, Y. Jin, B. Baldetorp, F. Mertens and J. Wennerberg, Complex karyotypes in flow cytometrically DNA-diploid squamous cell carcinomas of the head and neck, Br. J. Cancer 77 (1998), 1082-1088.

[22] F.J. Otto, High-resolution analysis of nuclear DNA employing the fluorochrome DAPI, in: Methods in Cell Biology, Vol. 41, San Diego, CA, 1994, pp. 211-217.

[23] J. Hemmer, W.F.P. Van Heerden, J. Polackova and K. Kraft, High-resolution DNA flow cytometry in papillary cystadenoma lymphomatosum (Warthin's tumour), J. Oral. Pathol. Med. 27 (1998), 405-406.

[24] J. Hemmer and E. Schön, Anticancer drug action assessed by serial DNA flow cytomety during induction chemotherapy in oral squamous cell carcinoma: impacts on the development of indivdualized treatment strategies, Chemother. 41 (1995), 214 221.

[25] J. Hemmer, J. Kreidler, K. Kraft and E. Schön, Monitoring of anticancer drug effects in vivo by serial DNA flow cytometry of oral carcinomas treated by intra-arterial 5-fluorouracil/cisplatin induction chemotherapy, Anticancer Res. 14 (1994), 20772084.

[26] M. Ghadimi, K. Heselmeyer-Haddad, G. Auer and T. Ried, Interphase cytogenetics: at the interface of genetics and morphology, Analyt. Cell. Pathol. 19 (1999), 3-6.

[27] F. Mertens, B. Johansson, M. Höglund and F. Mitelman, Chromosomal imbalance maps of malignant solid tumors: a cytogenetic survey of 3185 neoplasms, Cancer Res. 57 (1997), 27652780 .

[28] D.P. Cahill, C. Lengauer, J. Yu, G.J. Riggins, J.K.V. Wilson, S.D. Markovitz, K.W.Kinzler and B. Vogelstein, Mutations of mitotic checkpoint genes in human cancers, Nature 392 (1998), 223-224. 


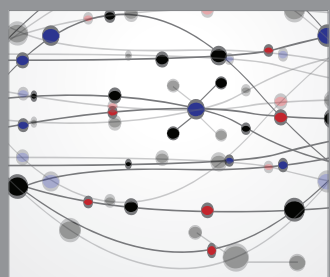

The Scientific World Journal
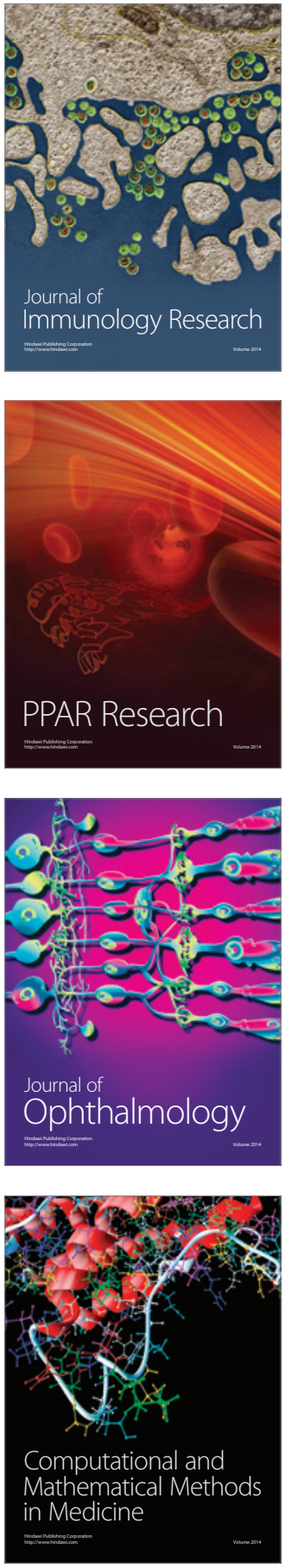

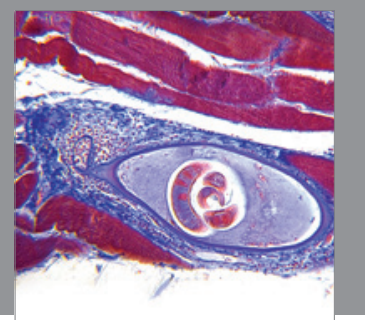

Gastroenterology

Research and Practice
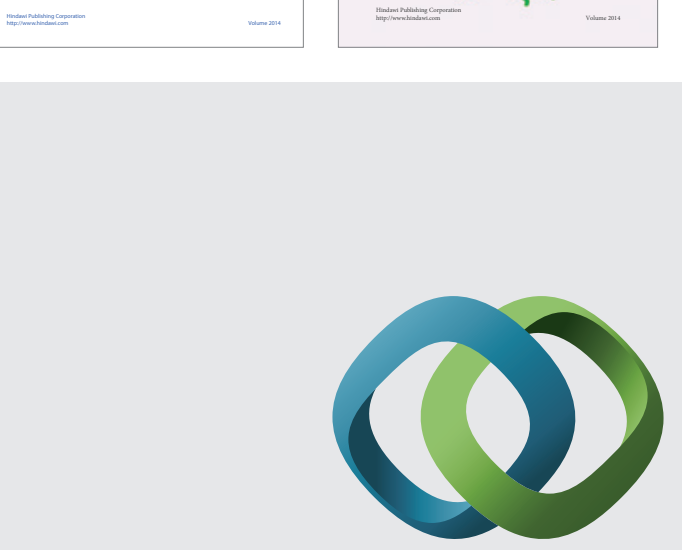

\section{Hindawi}

Submit your manuscripts at

http://www.hindawi.com
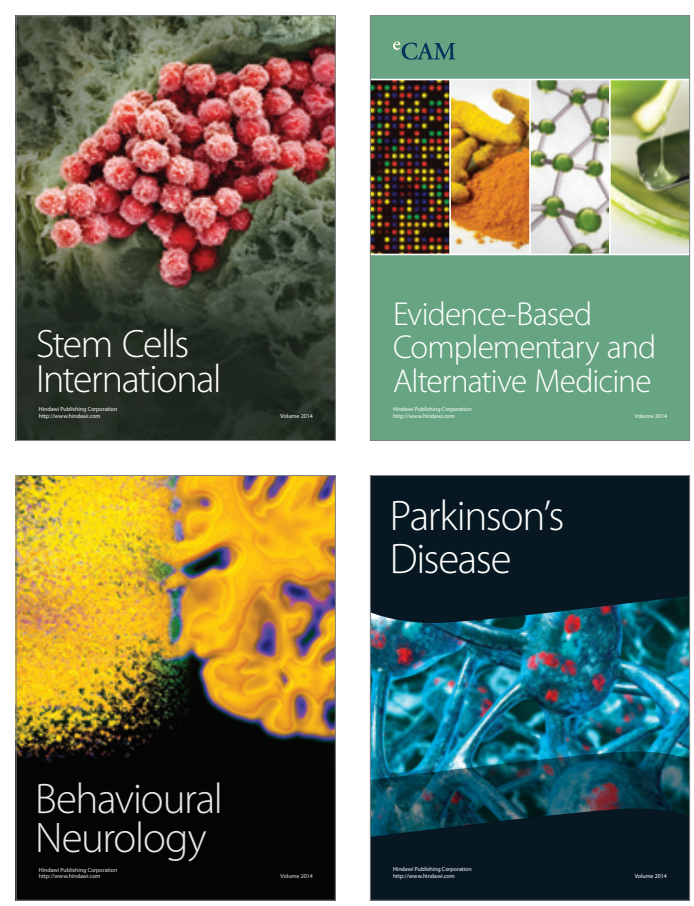

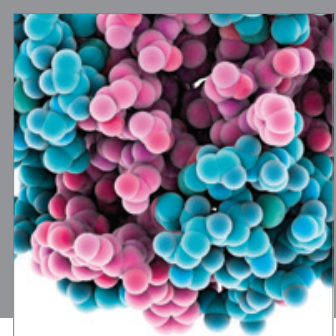

Journal of
Diabetes Research

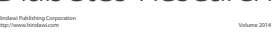

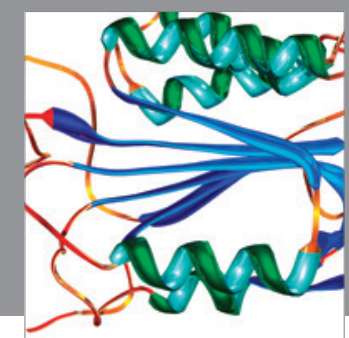

Disease Markers
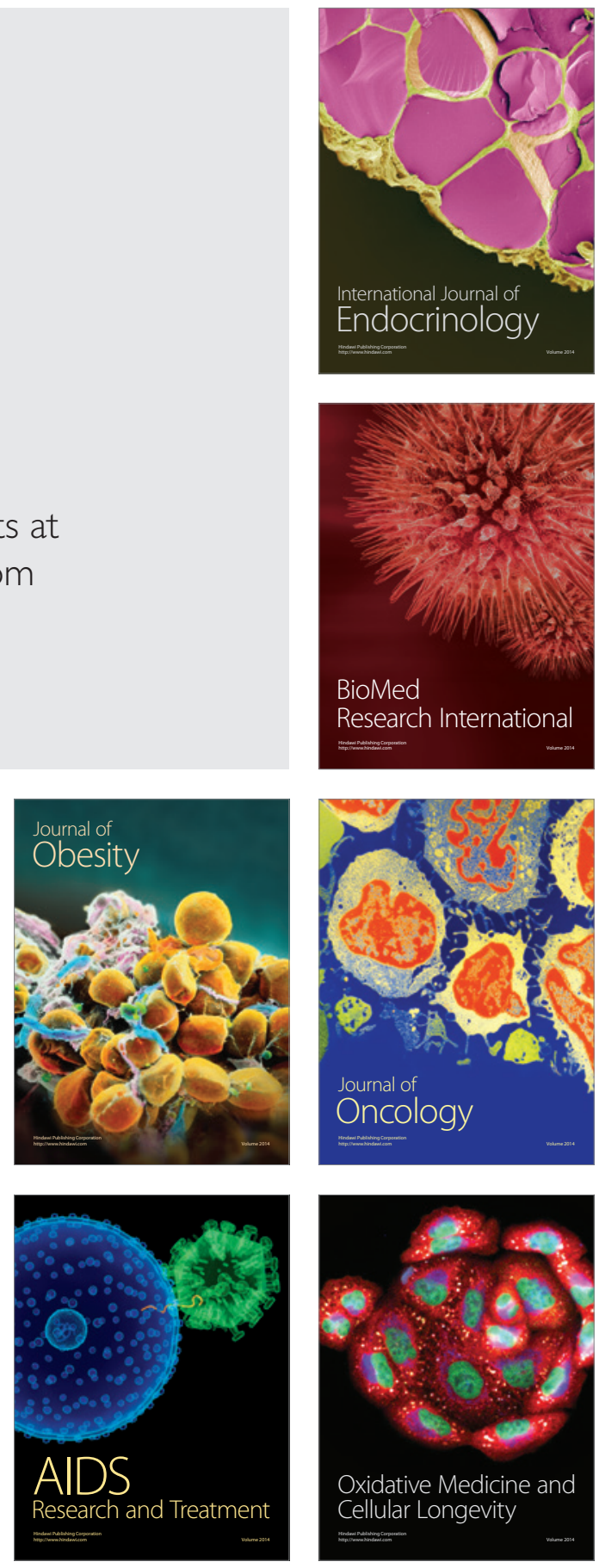